\title{
Modulation index effect on inverter based induction motor drive
}

\author{
Akhilesh Sharma ${ }^{1}$, Anandh N. ${ }^{2}$, Sarsing Gao ${ }^{3}$ \\ ${ }^{1,3}$ Electrical Engineering Department, North Eastern Regional Institute of Science \& Technology, Nirjuli, \\ Arunachal Pradesh, India \\ ${ }^{2}$ Department of Electrical and Electronics Engineering, Manipal Institute of Technology, Manipal Academy of Higher \\ Education, Manipal, Karnataka, India
}

\section{Article Info}

Article history:

Received Jan 23, 2020

Revised Apr 26, 2020

Accepted May 31, 2020

\section{Keywords:}

Induction Motor

Modulation Index

Neural Network

Space Vector PWM

\begin{abstract}
Due to a substantial increase in the use of inverter for numerous electrical appliances starting from domestics to industrial drives, an inverter may be directly connected to the power grid system. The dependency on an inverter has been increased over the years. Hence, the proper and efficient design of the inverter will lead to higher efficiency. One of the major challenges is the generation of suitable gate pulses for power switching devices, which in turn depends on the modulation index. The selection of proper modulation index will help in the production of the rated voltage. If the modulation index is less, the duration of on-time pulses will be less and hence, the device's conduction time is also less, thereby the output voltage of the inverter is reduced. A reduced voltage, when applied to an induction motor will have lower speed and even its performance will be sluggish. The speed of the motor improves when it is operated in a closed-loop for the same modulation index. This research paper tries to bring out the effect of modulation index on speed control of an induction motor based on an inverter for both open as well as closed-loop operation. The simulated results indicate that the modulation index in the vicinity to unity will provide rated voltage for the smooth operation of the motor.
\end{abstract}

This is an open access article under the CC BY-SA license.

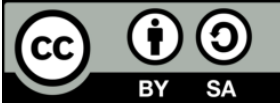

\section{Corresponding Author:}

Akhilesh Sharma,

Electrical Engineering Department,

North Eastern Regional Institute of Science \& Technology,

Nirjuli, Papum Pare, Arunachal Pradesh 791109, India.

Email: as@ nerist.ac.in

\section{INTRODUCTION}

Frequent fault on the power system, unavailability of power to remote location and availability of solar energy at such locations have increased the utility of inverter, as they serve as a standby ac power supplies from a DC source [1] to meet the load demand. Even, inverters are applied for the industrial drive during shut down or power failure due to fault. Hence, the operation of inverter plays an important role in such applications. The inverter circuit consists of many switching devices. To turn on these devices, proper triggering pulses are essential. The duration of these pulses depends on the switching frequency and its modulation index (MI) [2-7]. MI selection becomes important provided the switching frequency is constant.

With the advancement in the design of inverter, they are capable of providing the power needed for industrial drives. Mostly, these drives consist of induction motors (IM) because they have special features like simple, rugged in construction with minimum maintenance need, etc. Most importantly, they can operate 
at any environmental conditions. These motors are preferred for constant speed operation. The change in speed from no load to full load is small. Hence these motors are widely used in industries. Motors used in industries need continuous electrical power. Disruption in the electrical power leads to the complete shut down of the industries as electrical energy conversion is mostly based on the conventional sources of energy. The drive stoppage may be avoided, provided the motor drives systems are based on both inverter and conventional power plants. The inverter-based drives may be able to provide the rated voltage needed for the drives. The inverter output voltage depends on the switching pulses [8], which in turn is related to MI. So, there is a need for a proper selection of MI.

For a particular MI, the triggering pulses are generated that are used for switching the devices. The output voltage of a three-phase inverter is applied to a three-phase induction motor (IM), whose parameters are given in Table 1, in an open as well as closed-loop condition. In the closed-loop operation [10], many controllers like PID, fuzzy-logic [11] or neural network could be employed. In this paper, a NN controller [12-18] has been employed to control the error in the speed of the motor, generated from the difference of reference speed and motor speed. Thus, controlling the motor to follow the reference speed, while, in open-loop control, the speed of IM is independent of reference speed. In this paper, an attempt has been made to find the effect of MI on the speed of an IM and the results are obtained. The results indicate that the modulation index, near the unity, generates the triggering pulses of sufficient width to produce rated voltage for the motor. But when the MI is less than 0.8 or more than 1.25 , the width of the switching pulses so produced is less and hence the inverter output voltage reduces. Therefore, the motor takes a longer time to pick up the reference speed.

Table 1. Parameters of induction motor

\begin{tabular}{cc}
\hline Number of Poles & 4 \\
\hline Per Phase Stator \& Rotor Resistance & $0.90 \Omega ; 0.66 \Omega$ \\
Per Phase Stator \& Rotor Inductance & $0.00457 \mathrm{H} \mathrm{each}$ \\
Moment of inertia & $0.1384 \mathrm{Kg}-\mathrm{m}^{2}$ \\
Frequency & $50 \mathrm{~Hz}$ \\
Load Torque & $10 \mathrm{~N}-\mathrm{m}$ \\
DC source Voltage & $540 \mathrm{~V}$ \\
\hline
\end{tabular}

\section{MODULATION INDEX}

Consider two signals, a triangular wave and a DC signal, acting as a carrier and modulating signals respectively as shown in Figure 1 (i). When the triangular signal [19] is compared with the DC signal such that, the magnitude of the triangular becomes equal to that of DC signal, then the output will be constant until it becomes less than the DC signal as shown in Figure 1 (ii) and (iii) respectively, acting as triggering pulses for controlled power electronic devices $T_{1}$ and $T_{2}$ as shown in Figure 2. The width of the pulses depends upon the magnitude of the DC signal. The width of the pulse for $\mathrm{T}_{1}$ decreases as the magnitude of the DC source increases. At the same time, the pulse width for $\mathrm{T}_{2}$ increases thereby increasing the conduction period of $T_{2}$. The high and low duration pulses become equal provided the modulating signal has zero magnitudes. Since the amplitude of the modulated signal decides the width of the pulses, hence, this scheme of modulation is called as amplitude modulation [20]. Thus, this is defined as the ratio of the amplitude of the modulating signal, $\left(\mathrm{V}_{\mathrm{m}}\right)$ to that of the amplitude of the carrier wave, $\left(\mathrm{V}_{\mathrm{c}}\right)$, i.e.

$$
M I=\frac{V_{m}}{V_{c}}
$$

If $T_{c}$ is the time period of the triangular wave, then conduction periods for $T_{1}$ and $T_{2}$ are expressed as,

$$
\begin{aligned}
& t_{h}=\frac{T_{c}}{2}\left(1-\frac{V_{m}}{V_{c}}\right) \\
& t_{l}=\frac{T_{c}}{2}\left(1+\frac{V_{m}}{V_{c}}\right)
\end{aligned}
$$

Where $t_{h}$ and $t_{1}$ are the conduction time of $T_{1}$ and $T_{2}$ respectively.

Consider an inverter, as shown in Figure 2. The output voltage between nodes A and B will have a magnitude of either $\pm 0.5 \mathrm{~V}_{\mathrm{dc}}$ or 0 , depending on the DC modulating signal. This voltage has been referred to as pole voltage, $\mathrm{V}_{\mathrm{AO}}$ as indicated in Figure 2. The DC component of this voltage is evaluated as,

$$
V_{o}=0.5 V_{d c} \frac{V_{m}}{V_{c}}
$$




$$
V_{o}=V_{A O} \frac{V_{m}}{V_{c}}
$$

Equations (2) and (3) can be expressed in terms of modulation index (MI), as

$$
\begin{aligned}
& t_{h}=\frac{T_{c}}{2}(1-M I) \\
& t_{l}=\frac{T_{c}}{2}(1+M I)
\end{aligned}
$$

As can be seen from expression (4), the mean voltage becomes zero, when the magnitude of the modulating signal becomes zero i.e. the pulse width of both low and high signals are equal and hence the area under both halves are equal, making the average value of the DC component to be zero. Along with the DC component, the output will also have harmonics of integral multiples of the carrier frequency, while the frequency of lower order harmonics becomes equal to the carrier frequency.

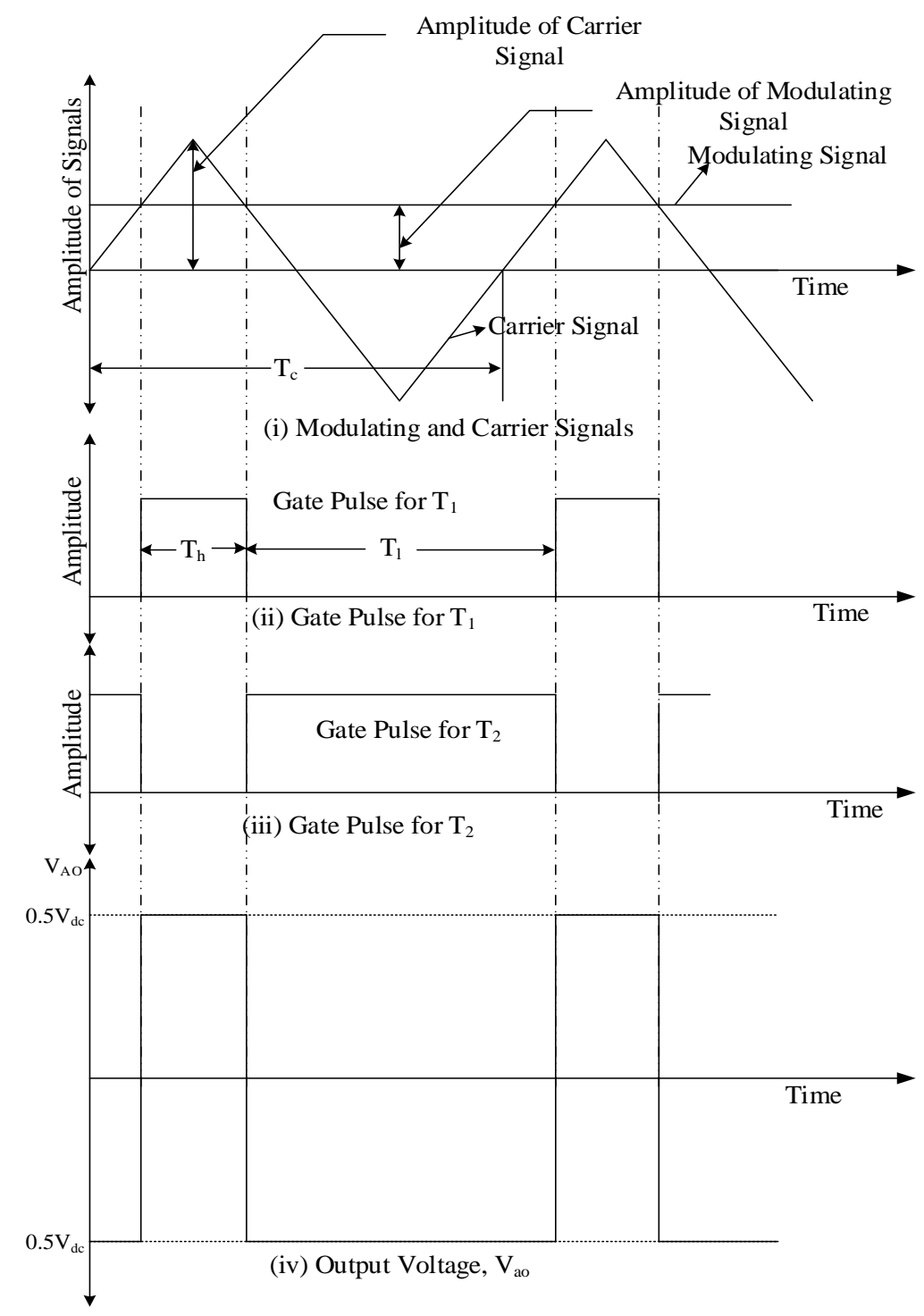

Figure 1. Generation of modulating and carrier signals, gate pulses and pole voltage

The DC modulating signal may be replaced by a sinusoidally varying signal [21] with a certain amplitude, phase and frequency. The frequency of this signal is quite less than the carrier frequency. This makes the modulating signal virtually constant over the high carrier frequency, making the average pole 
voltage to depend on the magnitude of the modulating signal. Thus, the pole voltage waveform will have a low-frequency component whose instantaneous magnitude is proportional to the modulating signal. It will also have a higher frequency harmonic voltage.

If DC is used as a modulating signal, there will be harmonic frequencies. These frequencies will be an integral multiple of the carrier frequency. But this does not happen, if DC is replaced by sinusoidally varying signal where pulse width depends on the frequency of modulating signal. This is visible from equations (2) and (3) respectively. Due to this, there will be harmonics in the pole voltages and there exists a band of frequencies in the vicinity to a carrier and its multiple frequencies. The band frequencies are formed by an integral multiple of the frequency of modulating signals. It is usual to have modulating frequency quite less in comparison with the carrier frequency, hence the frequency of the dominant harmonics will be in the close vicinity of carrier frequency and its integral multiple.

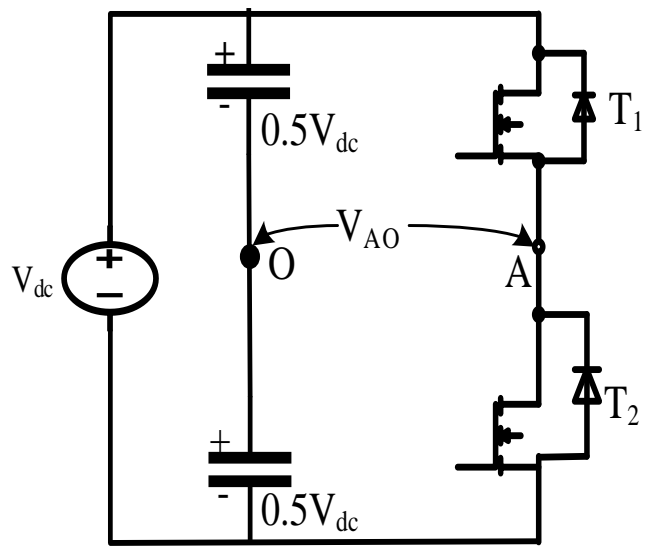

Figure 2. A simplified inverter topology

\section{SPACE VECTOR PULSE WIDTH MODULATION (SVPWM)}

This is a vector technique that is applied for pulse width modulation (PWM) for 3- $\Phi$ inverters. This scheme is widely used for generating gating signals for high voltage with low harmonic distortion, suitable for variable frequency industrial drives such as induction motor. This technique can be explained with the help of Figure 3. The circuit will produce two voltage levels. It consists of six controlled switches, $S_{1}$ to $S_{6}$ and a DC source voltage of " $\mathrm{V}_{\mathrm{s}}$ ". There are eight possible switching vectors [22], as depicted in Figure 4. The states $\mathrm{V}_{0}[000]$ and $\mathrm{V}_{7}[111]$ are null vectors while $\mathrm{V}_{1}-\mathrm{V}_{6}$ are active vectors. The null vector produces zero voltage while an active vector produces non-zero voltage. The space vector [23-25] voltage generation, other than these states, is shown in Figure 5. The required voltage vectors could be obtained based on equations (8) and (9) which could be extended to 3-dimensional space vector [26] as well. This establishes a rotating vector [27] and it is similar to a rotating flux developed in the stator of an induction motor. The rotating flux passes through the air gap to the rotor side. This technique could be extended to a multi-level inverter as well.

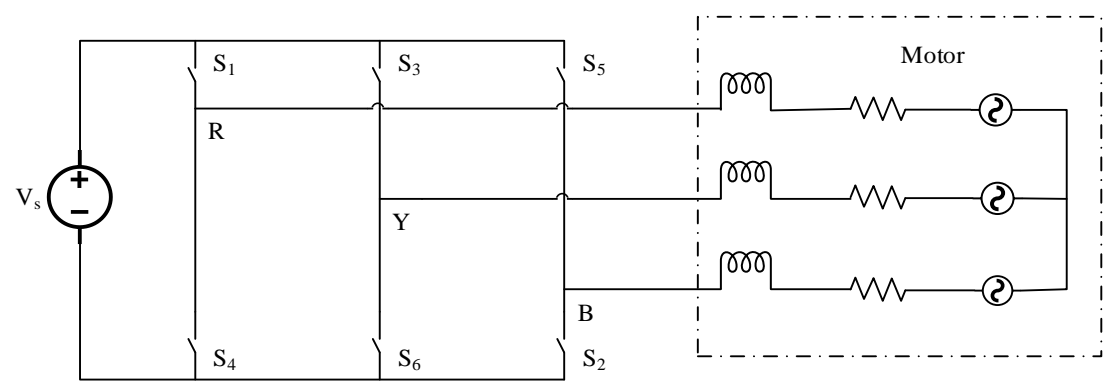

Figure 3: Inverter based motor load representation 
From Figure 5, the reference voltage, $\overline{V_{\text {ref }}}$, is expressed as, in equation (8). The corresponding line voltages are tabulated in Table 2.

$$
\begin{aligned}
& \overline{V_{\text {ref }}}=V_{1}\left(T_{1} / T_{s}\right)+V_{2}\left(T_{2} / T_{s}\right)+V_{3}\left(T_{3} / T_{s}\right) \\
& T_{1} /_{T_{s}}+T_{2} / T_{s}+T_{3} / T_{s}=1
\end{aligned}
$$

Here $T_{1}, T_{2}$ and $T_{3}$ are the periods through vectors $V_{1}, V_{2}$ and $V_{3}$ respectively, $T_{s}$ is sampling period.

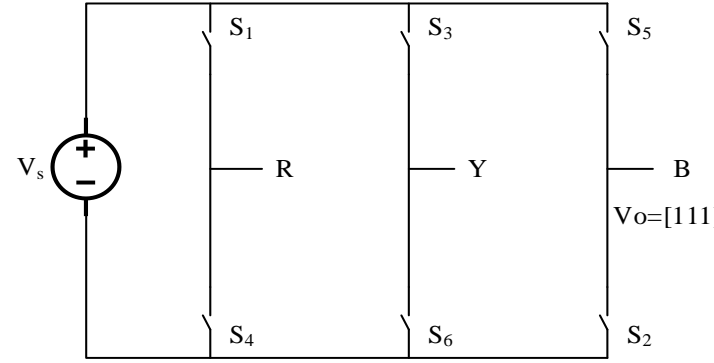

(i) State 1

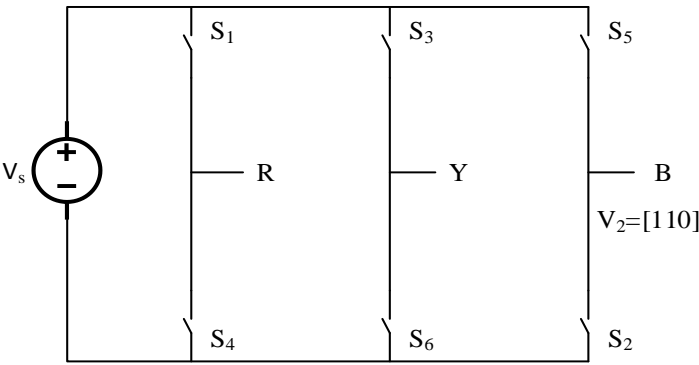

(iii) State 3

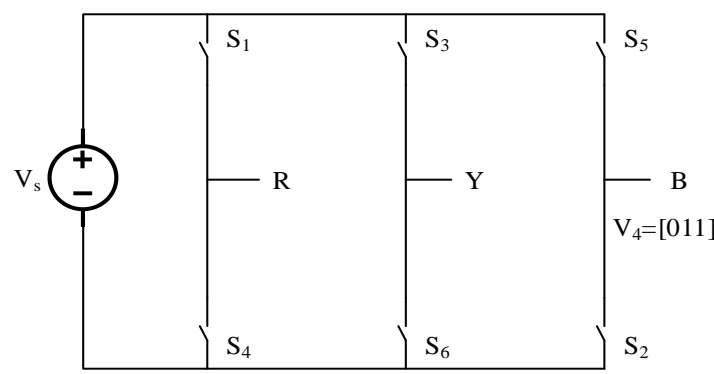

(i) State 5

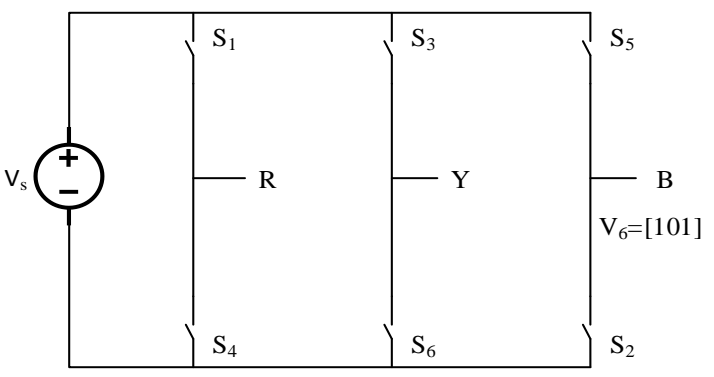

(iii) State 7

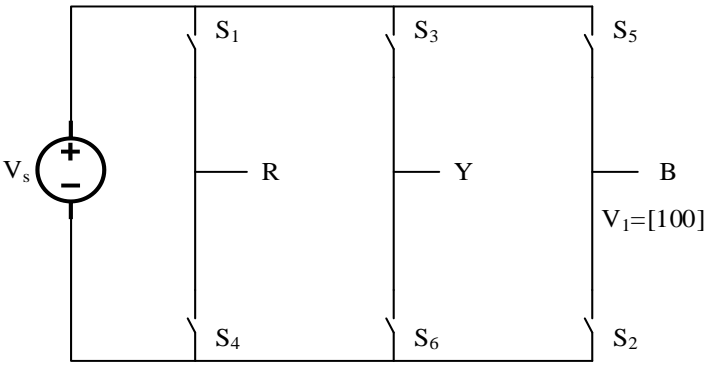

(ii) State 2

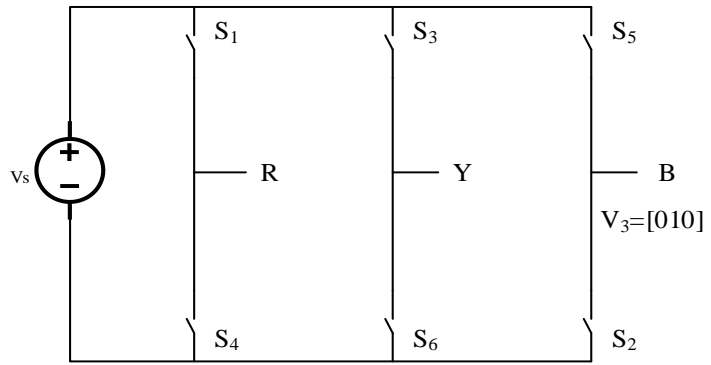

(iv) State 4

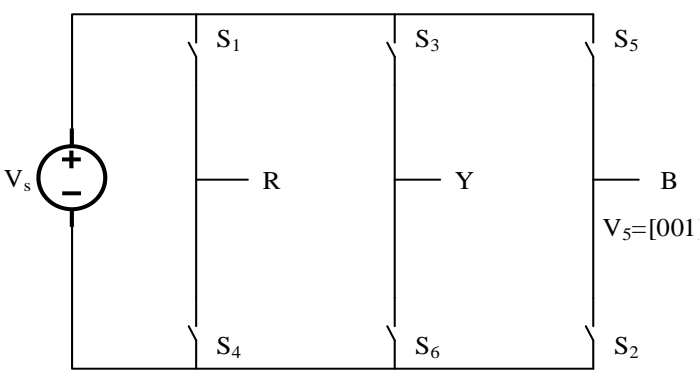

(ii) State 6

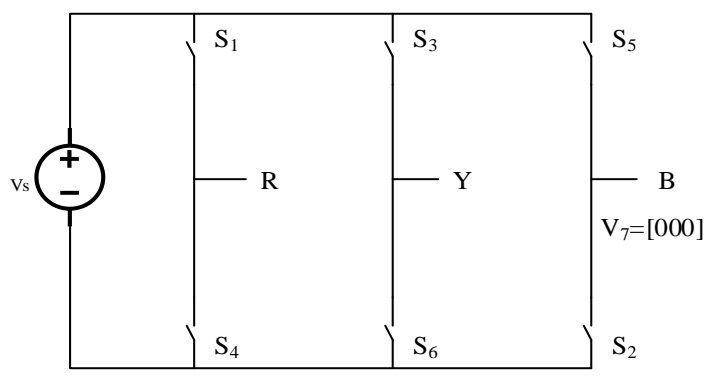

(iv) State 8

"1" indicates ON states of upper switches $\mathrm{S}_{1}, \mathrm{~S}_{3}$ or $\mathrm{S}_{5}$ while "0" shows ON status of lower switches $\mathrm{S}_{2}, \mathrm{~S}_{4}$ or $\mathrm{S}_{6}$,

$V_{0^{-}} V_{7}$ represent output voltages; $V_{0}$ and $V_{7}$ represent zero vectors; $V_{1}-V_{7}$ represent active vectors

Figure 4. Switching states of the two-level inverter 
Table 2. Voltage vector with its respective line voltage

\begin{tabular}{lcccccc}
\hline Voltage & \multicolumn{3}{c}{ Switching Vector } & \multicolumn{3}{c}{ Line Voltages } \\
Vector & $\mathrm{a}$ & $\mathrm{b}$ & $\mathrm{c}$ & $\mathrm{V}_{\mathrm{RY}}$ & $\mathrm{V}_{\mathrm{YB}}$ & $\mathrm{V}_{\mathrm{BR}}$ \\
\hline $\mathrm{V}_{\mathrm{o}}$ & 0 & 0 & 0 & 0 & 0 & 0 \\
$\mathrm{~V}_{1}$ & 1 & 0 & 0 & $\mathrm{Vs}$ & 0 & $-\mathrm{Vs}$ \\
$\mathrm{V}_{2}$ & 1 & 1 & 0 & 0 & $\mathrm{Vs}$ & $-\mathrm{Vs}$ \\
$\mathrm{V}_{3}$ & 0 & 1 & 0 & $-\mathrm{Vs}$ & $\mathrm{Vs}$ & 0 \\
$\mathrm{~V}_{4}$ & 0 & 1 & 1 & $-\mathrm{Vs}$ & 0 & $\mathrm{Vs}$ \\
$\mathrm{V}_{5}$ & 0 & 0 & 1 & 0 & $-\mathrm{Vs}$ & $\mathrm{Vs}$ \\
$\mathrm{V}_{6}$ & 1 & 0 & 1 & $\mathrm{Vs}$ & $-\mathrm{Vs}$ & 0 \\
$\mathrm{~V}_{7}$ & 1 & 1 & 1 & 0 & 0 & 0 \\
\hline
\end{tabular}

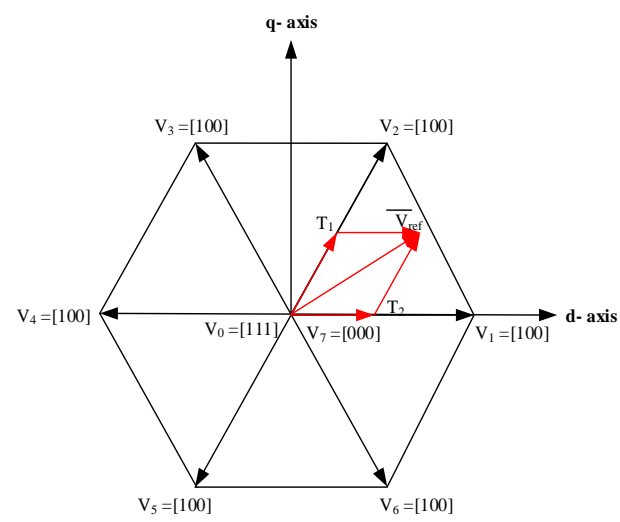

Figure 5. Space vector representation

\section{DYNAMIC MODELLING OF INDUCTION MOTOR}

An induction motor (IM) possesses many special features like robust in construction, high torque to inertia ratio, able to be utilized in any environment. Hence, most of the industrial drives use an induction motor. The stator of the induction motor requires a three-phase supply. This will establish MMF in the stator which in turn passes through the air gap, linked with the rotor circuit. Thus, an emf is induced in the rotor and it is similar to a transformer. Hence, the equivalent model of the transformer, with slight modification, could be used for IM. To draw, equivalent circuit diagram of IM, the assumptions [27,28] made are; (i) There exists uniform air gap, (ii) Sinusoidal flux distribution is uniform, (iii) Effect of change in the parameter is neglected, (iv) Effect of saturation is neglected.

The performance of the IM could be easily obtained based on its equivalent circuit model which is shown in Figure 6. This helps to study the steady-state characteristics, neglecting the transient state which occurs due to change in the load or even change in frequency, especially in variable speed drives. Mostly, these drives are based on converter circuits. The converters are fed through definite source voltage. Hence, there is a certain limit to draw the output power from them. Moreover, filters of definite size may be connected to shape the output voltage of the converters. This limits them to supply large transient power and makes essential to study the dynamic modelling of such drives.

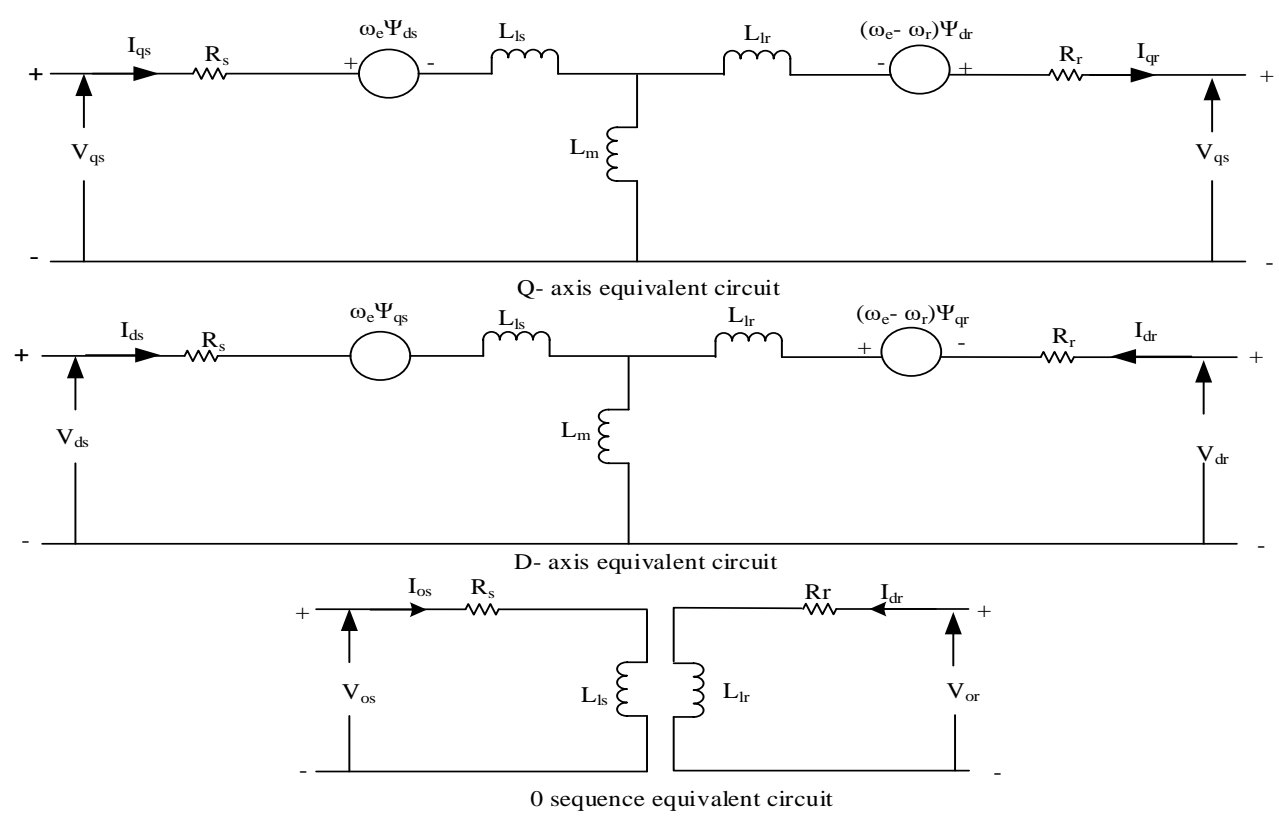

Figure 6: A dq0 equivalent circuit of an Induction Motor 


\subsection{Equivalent circuit of induction motor}

The dynamic behavior of the motor is due to the time-dependency of voltage and torque. Hence, they can be expressed in differential equations. But, this will increase system complexity. Figure 6 indicates dq0 equivalent circuit diagram of an IM. The dynamic equations of the motor are developed from its equivalent circuit $[9,11,24,27,29]$.

\subsection{Arbitrary reference frame}

This helps in representing a sinusoidally varying quantity into its DC equivalent. If this concept is used in IM, the control of the motor becomes easy, similar to a DC motor. Under this frame, it is assumed that the angular speed of the motor is rotated at the angular speed of the reference frame. Under this circumstance, the difference in angular speed becomes zero and thus a sinusoid signal looks like DC signal. This makes easy to develop small-signal equation out of the non-linear equation, describing the operating point by DC values only.

The equivalence between two and the three-phase machine could be achieved provided their MMF produced are equal. If there are $\mathrm{N}_{\mathrm{p}}$ number of windings per phase, for identical MMF, the two winding machines need $3 \mathrm{~Np} / 2$ turns per phase. The MMF of three-phase could be converted into two-phase whose axes are $d$ and q respectively. Considering $\alpha$ and $\beta$ as the axis of the arbitrary reference frame, the three-phase voltage is expressed as:

$$
\left[\begin{array}{l}
V_{\alpha} \\
V_{\beta}
\end{array}\right]=\frac{2}{3}\left[\begin{array}{ccc}
1 & 1 / 2 & -1 / 2 \\
0 & \sqrt{3} / 2 & -\sqrt{3} / 2
\end{array}\right]\left[\begin{array}{l}
V_{R} \\
V_{Y} \\
V_{B}
\end{array}\right]
$$

The direct and quadrature axis voltages are expressed as,

$$
\left[\begin{array}{l}
V_{d} \\
V_{q}
\end{array}\right]=\left[\begin{array}{cc}
\cos \theta & \sin \theta \\
-\sin \theta & \cos \theta
\end{array}\right]\left[\begin{array}{l}
V_{\alpha} \\
V_{\beta}
\end{array}\right]
$$

The instantaneous rotor and stator current equations are,

$$
\begin{aligned}
& {\left[\begin{array}{l}
i_{\alpha} \\
i_{\beta}
\end{array}\right]=\left[\begin{array}{cc}
\cos \theta & -\sin \theta \\
\sin \theta & \cos \theta
\end{array}\right]\left[\begin{array}{l}
i_{r d} \\
i_{r q}
\end{array}\right]} \\
& {\left[\begin{array}{l}
i_{R} \\
i_{Y} \\
i_{B}
\end{array}\right]=-\frac{2}{3}\left[\begin{array}{cc}
1 / 2 & \sqrt{3} / 2 \\
1 / 2 & \sqrt{3} / 2
\end{array}\right]\left[\begin{array}{l}
i_{\alpha} \\
i_{\beta}
\end{array}\right]}
\end{aligned}
$$

Where, $\mathrm{V}_{\mathrm{R}}, \mathrm{V}_{\mathrm{Y}}$ and $\mathrm{V}_{\mathrm{B}}$ are the stator voltages, $\mathrm{V}_{\mathrm{d}}$ and $\mathrm{V}_{\mathrm{q}}$ are the direct and quadrature axis voltages. $i_{\text {rd }}$ and $i_{\text {rq }}$ are the instantaneous dq rotor currents, $V_{\alpha}$ and $V_{\beta}$ are arbitrary reference frame voltages with $i_{\alpha}$ and $i_{\beta}$ as their instantaneous currents, while $i_{R}$, $i_{Y}$ and $i_{B}$ be the instantaneous stator currents. The equations (10) to (13) represents the association of currents and voltages in different frames.

The dynamic model of IM may be achieved by establishing an equivalence between 3- $\Phi$ and 2- $\Phi$ machines. This is based on the magnitude of MMF created in windings of both machines when the equal magnitude of currents is allowed to flow through these windings. So, $\mathrm{N}_{\mathrm{p}}$ of 3- $\Phi$ will produce the same MMF, provided two winding machines have $3 \mathrm{~N}_{\mathrm{p}} / 2$ number of turns per phase. The direct (d) and quadrature (q) axes MMF are found by resolving MMF of the three-phase along these axes. The equation, thus developed, will have some common factor that could be eliminated, except currents in windings. From Figure 6, the dq0 stator and rotor voltages, under balanced conditions, can be expressed easily [27, 31]. From the equivalent circuit, the voltage equations are,

$$
\begin{aligned}
& V_{q s}=R_{s} i_{q s}+\frac{d \psi_{q s}}{d t}+\omega_{e} \psi_{d s} \\
& V_{q r}=R_{s} i_{d s}+\frac{d \psi_{d s}}{d t}-\omega_{e} \psi_{q s} \\
& V_{q r}=R_{r} i_{q r}+\frac{d \psi_{q r}}{d t}+\left(\omega_{e}-\omega_{r}\right) \psi_{d r} \\
& V_{d r}=R_{r} i_{d r}+\frac{d \psi_{d r}}{d t}-\left(\omega_{e}-\omega_{r}\right) \psi_{q r} \\
& V_{o s}=R_{s} i_{o s}+\frac{d o_{o s}}{d t} \\
& V_{o r}=R_{r} i_{o r}+\frac{d \lambda_{o r}}{d t}
\end{aligned}
$$


Where, $\psi_{q s}=L_{l s} i_{q s}+L_{m}\left(i_{q s}+i_{q r}\right)$

$\psi_{q r}=L_{l r} i_{q r}+L_{m}\left(i_{q s}+i_{q r}\right)$

$\psi_{d s}=L_{l s} i_{d s}+L_{m}\left(i_{d s}+i_{d r}\right)$

$\psi_{d r}=L_{l s} i_{d r}+L_{m}\left(i_{d s}+i_{d r}\right)$

$\lambda_{o s}=L_{l s} i_{o s}$

$\lambda_{\text {or }}=L_{\text {lr }} i_{\text {or }}$

$\lambda_{o s}$ and $\lambda_{\text {or }}$ are the zero-sequence flux linkages.

Where, $\omega_{e}$ and $\omega_{r}$ are arbitrary angular and stator angular frequency respectively.

The electromagnetic torque is expressed as,

$$
T_{e}=\frac{3}{2} \frac{P}{2} L_{m}\left(i_{q s} i_{d r}-i_{d s} i_{q r}\right)
$$

Also,

$$
T_{e}=T_{l}+\frac{2}{P} J \frac{d \omega_{r}}{d t}
$$

$\mathrm{T}_{1}$ and $\mathrm{J}$ represent load torque and moment of inertia respectively.

\section{CLOSED-LOOP CONTROL}

The closed-loop operation usually provides more accurate results at the cost of increasing circuit complexity. Industrial drives employ different types of motors by varying ac supply. The speed of these drives changes, due to factors like change in the supply voltage or change in load torques. Under these variations, the drive speed varies. this leads to development of speed control by many method, notable, direct torque of V/F methods [30,31]. There are certain applications, where the speed of the industrial drives should be constant under any circumstances. Under such a situation, the effect of any of the parameters should not reduce the speed of such drives. This is possible only if the drive system is operated in a closed-loop. The closed-loop operation will have no effect of change in parameters on the industrial drives.

A simple diagram of a closed-loop system is shown in Figure 7. As seen from the Figure, that an error signal, $\mathrm{E}(\mathrm{s})$, is generated by subtracting plant output, $\mathrm{Y}(\mathrm{s})$, from the reference signal, $\mathrm{R}(\mathrm{s})$. A controller of gain, $G_{c}(s)$, must be able to control the error. If $G_{p}(s)$ is the gain of the plant, then the overall transfer function is expressed in (30).

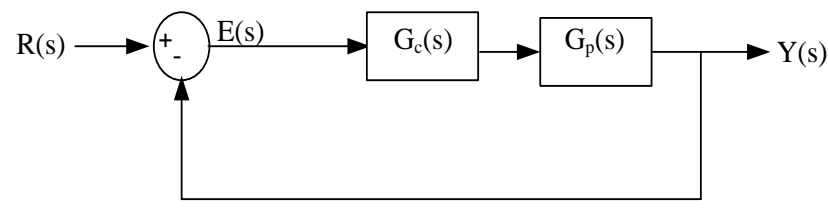

Figure 7. Closed-loop representation of a system

$$
\begin{aligned}
& E(s)=R(s)-Y(s) \\
& Y(s)=G_{c}(s) * G_{p}(s) * E(s)
\end{aligned}
$$

The overall transfer function, TF, is expressed as,

$$
T F=\frac{Y(s)}{R(s)}=\frac{G_{c}(s) * G_{p}(s)}{1+G_{c}(s) * G_{p}(s)}
$$

\subsection{Neural network (NN) architecture}

It is based on the interception of a neuron, a basic unit of the nervous system, on which the message is transmitted from the brain to different parts of the human body and back to the brain. Each neuron has a transmitter and a receiver through which these messages are transmitted and received. This scheme of 
transmitting and receiving can also be applied to solve real-life series problems based on certain set of rules. Hence, it can be said that an NN has a sequence of set of rules that is proficient to identify fundamental associations in a set of information in such a manner that is similar to the human brain. An NN could be natural like message transmission and receiving in human beings or artificial to solve real-life problems by human beings. It has a feature to adapt itself with the change in inputs i.e. the network can produce the most suitable result without changing its structure.

Neural networks learn itself from the preload task by analyzing training samples from the task which have been pre-loaded. For example, an object recognition system may contain thousands of labeled images of things like glass, tables, etc. It would find graphical patterns of the images that are consistently correlated with specific labels. In general, an NN contains thousands or even more simple processing nodes. These nodes are closely linked. These nets are ordered into strata of nodes, namely, input, hidden and output nodes. The nets could be "feed-forward," or "feed-backward". In feed-forward architecture, the data moves only in the forward direction. A single node may receive and transmit data from several nodes in a layer underneath and above it. While, in feed-backward, some portion of the output is fed-back to train the network. In the network, each node has a specific weight, indicated by "W $\mathrm{W}_{\mathrm{i}}$ ". When the network is live, the node accepts altered data that gets multiplied by its weight " $\mathrm{W}_{\mathrm{i}}$ ", summed up with bias " $\mathrm{b}$ " resulting in a single number. If the number is less than a threshold value, the node does not pass any data to the subsequent layer. But, if the number is greater than the threshold value, the node transmits the number. A simplified multi-layer NN structure [32] is shown in Figure 8.

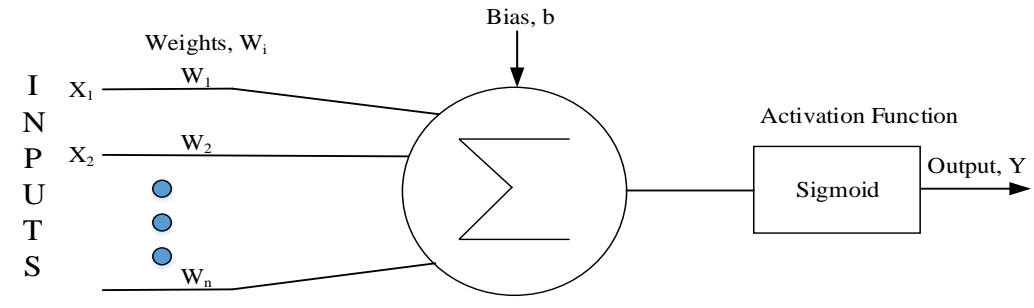

Figure 8. A simplified multi-layer NN structure

Initially, weights and thresholds function are randomly considered, then, the training of NN starts. The data to be trained is fed through input layers, then, it passes through successive layers. At each successive layer, it gets multiplied to its weights. The resultant gets added together until radically transformed data is available at the output layer. Training is continued by continuously adjusting the weights and thresholds until consistent results are obtained at the output.

A block diagram representation of inverter connected to a motor load has been shown in Figure 9. In this case, the dynamic load considered is an IM. The motor speed is measured and it is converted into its equivalent frequency. Even, the reference speed in rpm has been converted to its frequency domain. Then, the frequency error is measured. These values are stored to tune the NN controller. Initially, the weights have been randomly assumed. A sigmoid has been used as an activation function. The controller tunes up the error so that it is minimized. The output of the controller, thus obtained, is a frequency signal. This signal, along with a particular modulation index, is used to generate gate pulses for the inverter which controls the RMS output voltage applied to the IM.

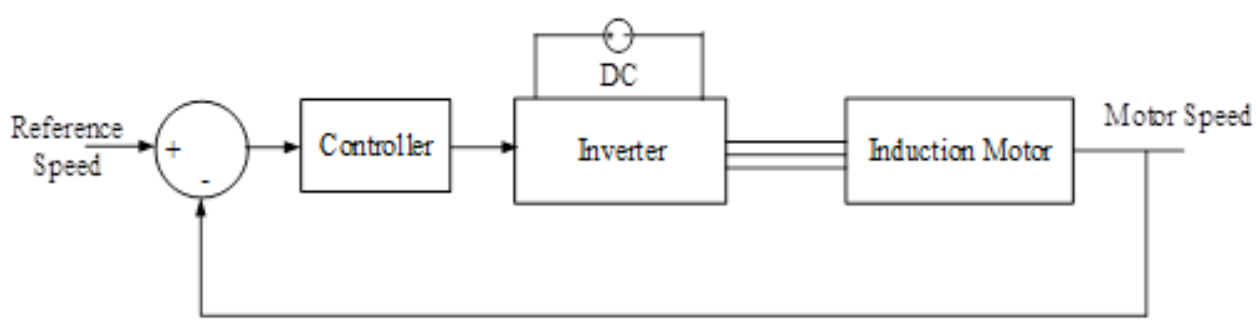

Figure 9. Closed loop of induction motor 


\section{RESEARCH METHOD}

Based on the sections, discussed above, Simulink models have been developed in MATLAB 16a. The implemented model is depicted in Figure 10. For a particular MI, the switching pulses for an inverter using space vector modulation have been generated by considering the sinusoidal wave of $50 \mathrm{~Hz}$ as reference signal. A triangular wave, used as a carrier signal, has a carrier frequency of $720 \mathrm{~Hz}$. The comparison of these two signals is used to generate triggering pulses for the power electronic controlled switches, producing a step alternating voltage. This alternating voltage has been shaped into a sinusoidally varying voltage using a low pass filter (LPF). It is, then, applied to the stator of a three-phase induction motor, modelled in a stationary reference frame whose parameters are given in Table 1. This provides an open-loop operation of the inverter-based control of induction motor.

In the closed-loop, for a known MI, measured speed of IM is converted into its frequency domain. This is compared with the equivalent frequency of the reference speed. The error thus generated is minimized with a feed-forward neural network (NN) with 15 layers, one input, one output and a sigmoid activation function. The NN tunes the error signal so that it becomes zero, providing an output frequency equal to the reference frequency. This frequency is used for generating a sinusoidal reference signal, while the carrier frequency remains unchanged. Comparision of the two signals produces triggering pulses using SVPWM techniques, whose width of the pulses depend upon the reference frequency, thus controlling the on time of the switches. This establishes a closed-loop operation.

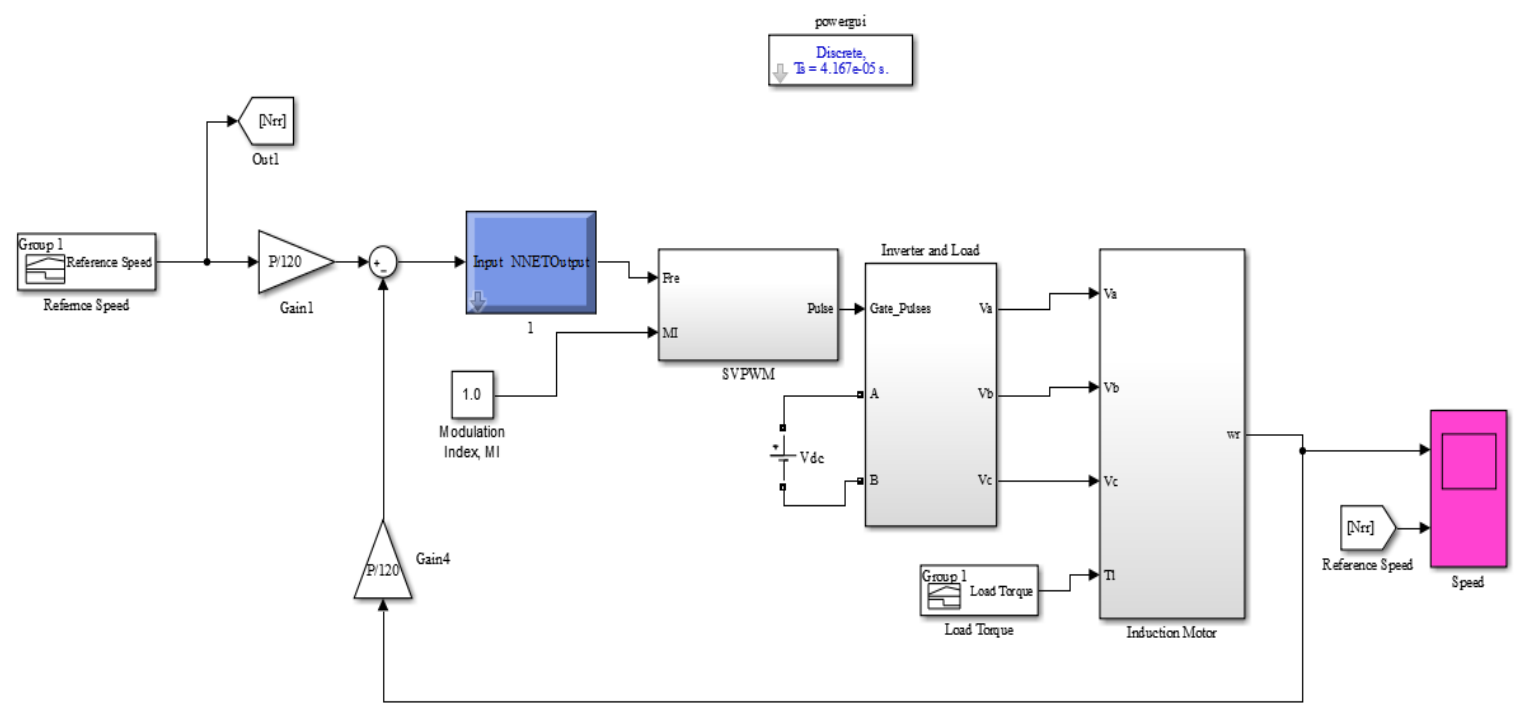

Figure 10: Closed-loop simulink model of induction motor

\section{RESULTS AND DISCUSSION}

The various results obtained are depicted in Figure 11 to Figure 13 for both open-loop and closedloop control. Figure 11 indicates the line voltage of one phase with its corresponding RMS value. These values are $359.9 \mathrm{~V}, 388.8 \mathrm{~V}, 415.6 \mathrm{~V}, 427.8 \mathrm{~V}, 406.9 \mathrm{~V}$, and $384.1 \mathrm{~V}$ respectively for MI variations from 0.6 to 1.5. The deviation in the RMS voltage is due to the width of the pulses. For lower MI, the width of the pulses for upper power switches decreases while the width of the pulses for lower switch increases thereby producing lower RMS voltages. Under this case, it is termed as under-modulation. As the modulation index reaches unity, the maximum RMS voltage of $427.8 \mathrm{~V}$ is obtained. At this modulation index, the width of pulses for both lower and upper switches are equal. The reverse occurs, when MI is greater than unity. Under this case, it is termed as over-modulation. Therefore, the RMS voltage reduces to $384.1 \mathrm{~V}$ for $1.5 \mathrm{MI}$. The percentage drop in voltage from unity MI to $1.5 \mathrm{MI}$ is a $10.22 \%$. For different MI, line voltages are tabulated in Table 3.

Figure 12 indicates an open-loop speed control of the IM with different MI. It is visible from the Figure that the maximum speed of IM is $1476 \mathrm{rpm}$ which is achieved at a unity MI for a load torque of $10 \mathrm{~N}$ $\mathrm{m}$. The speed decreases with either an increase or a decrease in MI from unity. In the under-modulation, the percentage speed variation is $2.37 \%$ while in over-modulation, this variation is $1.01 \%$. This is due to less 
RMS voltage applied to the stator of MI. Closer to rated voltage applied to the motor, higher will be the speed of IM, closer to no-load speed. The stator is connected to the output of the inverter whose line voltages changes from $359.9 \mathrm{~V}$ to $427.8 \mathrm{~V}$, therefore, the settling time (ST) of the motor is different. It varies from $2.88 \mathrm{sec}$ at $0.6 \mathrm{MI}$ to $0.8299 \mathrm{sec}$ at unity MI. When the rated voltage is applied to the motor, the settling time of the motor is minimum. The ST increases for under-modulation as well as over-modulation. Table 2 shows the speed of the motor and settling time for different MI.

Table 3. Line voltages, speed and settling time (ST) with variations in MI

\begin{tabular}{lccccccc}
\hline Parameters & & \multicolumn{5}{c}{ Modulation Index } \\
& & 0.600 & 0.700 & 0.800 & 1.000 & 1.250 \\
\hline RMS Voltage (V) & & 359.9 & 388.8 & 415.6 & 427.8 & 406.9 & 384.1 \\
Open-loop & Speed (rpm) & 1441 & 1458 & 1468 & 1476 & 1466 \\
Closed-loop & ST (secs) & 2.880 & 1.632 & 1.035 & 0.829 & 1.063 & 1.627 \\
& 1000 rpm & 983.3 & 983.1 & 998.7 & 999.9 & 997.2 & 991.4 \\
& ST (secs) & 0.516 & 0.336 & 0.263 & 0.214 & 0.288 & 0.386 \\
& 1500 rpm & 1438 & 1462 & 1464 & 1476 & 1469 & 1461 \\
& ST (secs) & 3.567 & 3.429 & 3.269 & 3.273 & 3.328 & 3.496 \\
\hline
\end{tabular}

In the closed-loop operation, the simulated results are presented in Figure 13. The reference speed has been set to $1000 \mathrm{rpm}$ whose frequency is $33.33 \mathrm{~Hz}$. A load torque of $10 \mathrm{~N}$-m has been applied to the motor. During acceleration, the NN controller can minimize the error in speed so the motor takes less time to reach a steady-state condition. The settling time is $0.5167 \mathrm{sec}$ at a speed of $983.3 \mathrm{rpm}$ for $0.6 \mathrm{MI}$. When the reference speed is stepped to $1500 \mathrm{rpm}$, the synchronous speed of the motor, at a time, $\mathrm{t}=3 \mathrm{sec}$, it settles at a speed of $1438 \mathrm{rpm}$ having a settling time of $0.567 \mathrm{sec}$. During this, the percentage errors in the speed are $1.67 \%$ and $4.13 \%$ respectively. When MI is taken as unity, speed of the motor becomes 999.9 rpm with a settling time of $0.2143 \mathrm{sec}$. The speed becomes $1476 \mathrm{rpm}$ at $3.273 \mathrm{sec}$ with percentage errors of almost zero percentage and $1.6 \%$ for reference speed of $1000 \mathrm{rpm}$ and $1500 \mathrm{rpm}$ respectively. The speed of IM decreases as MI increases beyond unity. These parameters are recorded in Table 2.

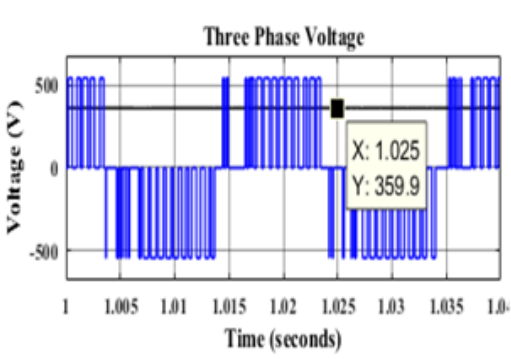

(a)

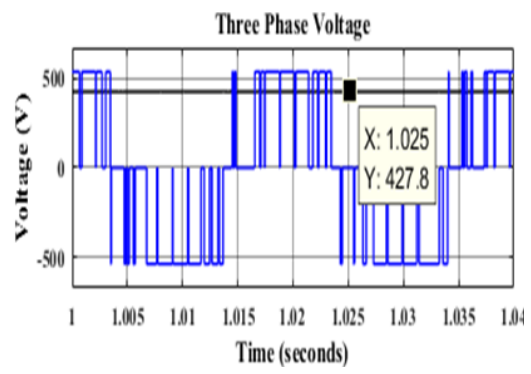

(d)

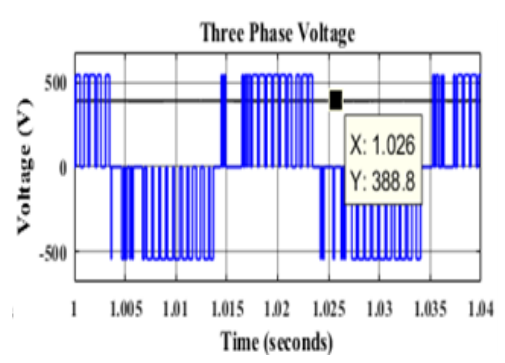

(b)

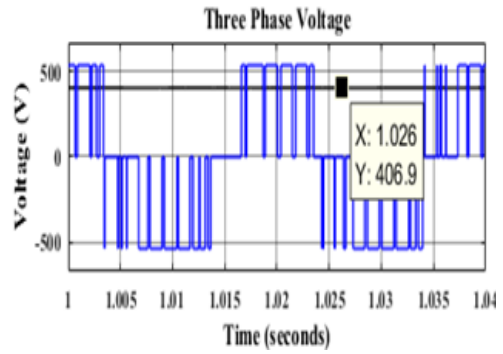

(e)

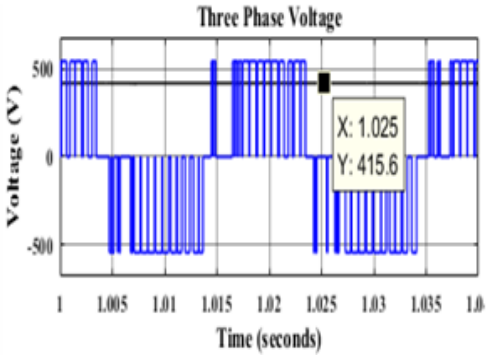

(c)

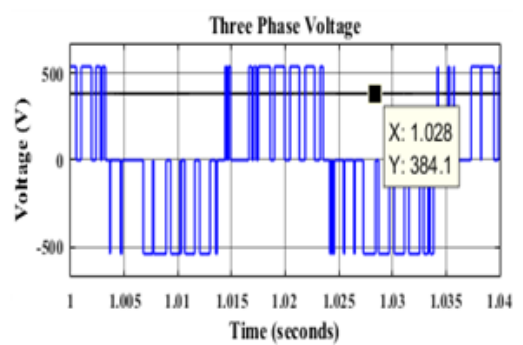

(f)

Figure 11. Line voltage waveform with various $\mathrm{MI}$, (a) $\mathrm{MI}=0.6$, (b) $\mathrm{MI}=0.7$, (c) $\mathrm{MI}=0.8$, (d) $\mathrm{MI}=1.0$, (e) $\mathrm{MI}=1.25$, (f) $\mathrm{MI}=1.5$ 


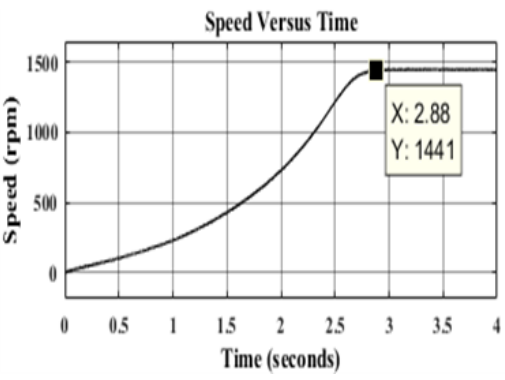

(a)

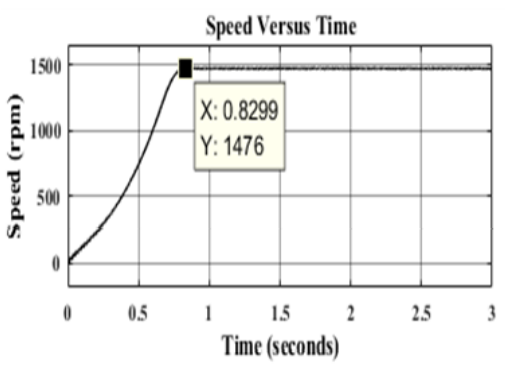

(d)

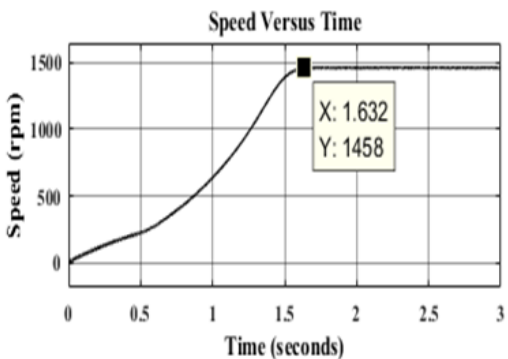

(b)

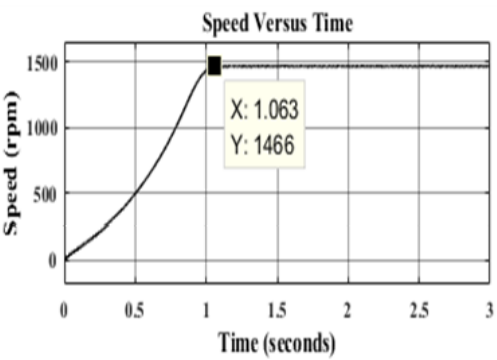

(e)

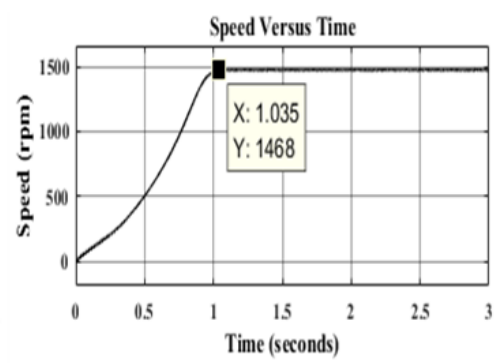

(c)

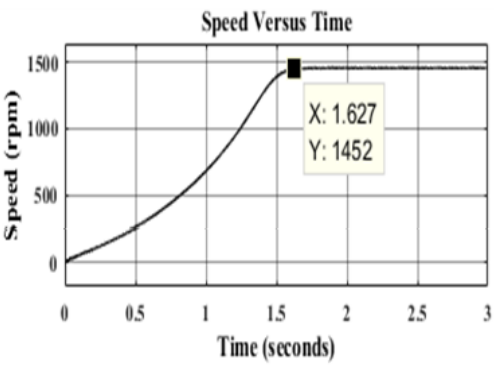

(f)

Figure 12. Open-loop speed control of induction motor, (a) Speed for 0.6, (b) Speed for 0.7, (c) Speed for 0.8 , (d) Speed for 1.0, (e) Speed for 1.25, (f) Speed for 1.5

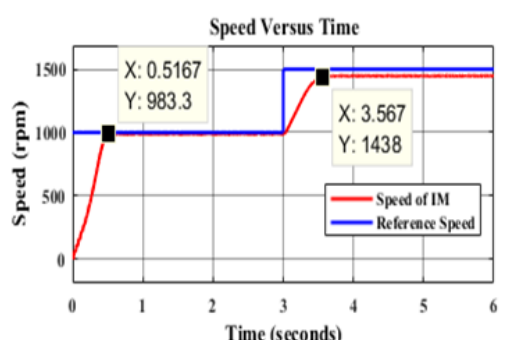

(a)

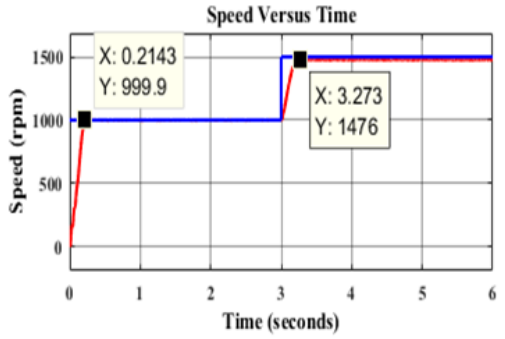

(d)

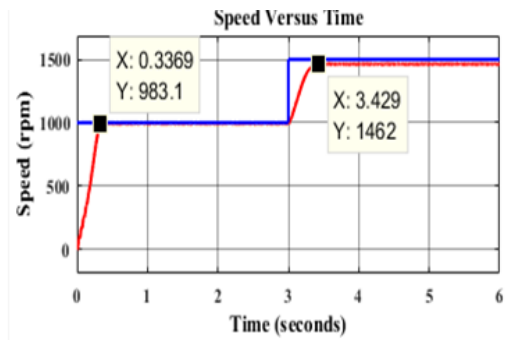

(b)

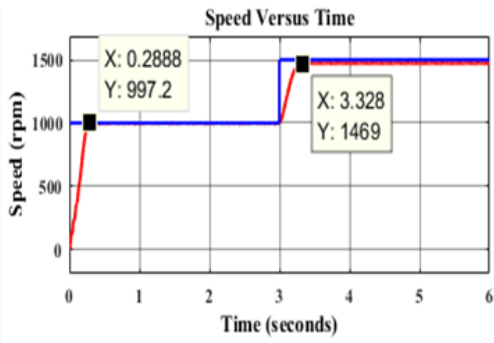

(e)

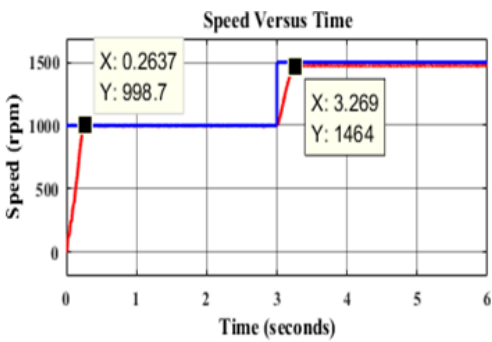

(c)

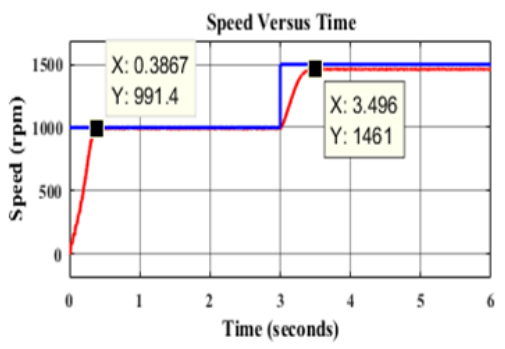

(f)

Figure 13. Closed-loop speed control of IM with variable reference speed and variations in MI,

(a) Speed for 0.6 MI, (b) Speed for 0.7 MI, (c) Speed for 0.8 MI, (d) Speed for 1.0 MI, (e) Speed for 1.25 MI, (f) Speed for $1.5 \mathrm{MI}$

\section{CONCLUSION}

The no-load voltage results indicate that the magnitude of the inverter voltages depends on the modulation index. As MI reaches unity, the RMS voltage also increases accordingly, giving rise to the maximum voltage at unity MI. The maximum RMS voltage is $427.8 \mathrm{~V}$. The RMS output voltage decreases beyond unity MI. Thus, indicating that the inverter voltage may be controlled by varying modulation index. When a motor is connected to the inverter, the speed may be controlled by controlling MI. The maximum 
speed of the motor at no-load, in open-loop control, is $1476 \mathrm{rpm}$, while it traces reference speeds of $1000 \mathrm{rpm}$ and $1500 \mathrm{rpm}$ in closed-loop. In the open-loop, the speed of the motor is independent of reference speed. But, in the closed-loop control, the motor follows the reference speed with different settling times. The settling time of motor reduces as MI approaches to unity. Again, beyond unity MI, the settling time increases. This indicates the dependency of settling time on MI. It is also seen that the speed of the motor depends on the variations of MI. For the satisfactory operation of the motor, the MI should be in the vicinity of unity.

\section{REFERENCES}

[1] Y. Babkrani, A. Naddami, and M. Hilal, "A smart cascaded H-bridge multilevel inverter with an optimized modulation technique increasing the quality and reducing harmonics," International Journal of Power Electronics and Drive System (IJPEDS), Vol. 10, No. 4, pp. 1852-1862, 2019.

[2] A. Solangi, R. Saikh, N.K. Pathan, M. Gul, F. Umer, and Z. A. Memo, "Effects of Modulation Index on Harmonics of SP-PWM Inverter Supplying Universal Motor," International Journal of Advanced Computer Science and Applications, Vol. 9, No. 7, pp. 167-174, 2018.

[3] A. Hren, and F. Mihalic, "An Improved SPWM-Based Control with Over-Modulation Strategy of the Third Harmonic Elimination for a Single-Phase Inverter,” Journal of Energies, MDPI, pp. 1-20, 2018.

[4] N. Ismail, A. Permadi, A. Risdiyanto, B. Susanto, and M. A. Ramdhani, "The Effect of Amplitude Modulation Index and Frequency Modulation Index on Total Harmonic Distortion in 1-Phase Inverter," IOP Conf. Series: Materials Science and Engineering, pp. 1-6, 2017.

[5] E. H. E. Aboadla, S. Khan, M. H. Habaebi, T. Gunawan, B. A. Hamidah, and M. B. Yaacob, "Effect of Modulation Index of Pulse Width Modulation Inverter on Total Harmonic Distortion for Sinusoidal," International Conference on Intelligent Systems Engineering, pp. 192-196, 2016.

[6] J.ILLeon, S. Kouro, L. G. Franquelo, J. Rodriguez, and B. Wu, "The Essential Role and the Continuous Evolution of Modulation Techniques for Voltage Source Inverters in Past, Present and Future Power Electronics," IEEE Transactions on Industrial Electronics, Vol.63, No.5, pp. 2688-2701, 2016.

[7] Jani Rushiraj G., and P.N. Kapil, "Analysis of Different Modulation Techniques for Multilevel Inverters," IEEE International Conference on Power Electronics, Intelligent Control and Energy Systems, pp. 3017-3022, 2016.

[8] M. A. Hannan, J. A. Ali, P. J. Ker, A. Mohamed, M. S. H. Lipu, and A. Hussain, "Switching Techniques and Intelligent Controllers for Induction Motor Drive: Issues and Recommendations," IEEE Access, Vol. 6, pp. 4748947510, 2018

[9] V.S. Bharath, and G. Mani, "Closed-Loop Analysis of Multilevel Inverter Fed Drives," International Journal of Power Electronics and Drive System, Vol. 4, No. 3, pp. 337-342, 2014.

[10] Bharatiraja C., R.K. Pongiannan, A. Yusuff, Mohd. Tariq, T. Maddileti, and T. Kumar, "A simple switching ontime calculation revision in multilevel inverter-space vector modulation to achieving extended voltage boundary operation," International Journal of Power Electronics and Drive System, Vol. 10, No. 2, pp. 653-661, 2019.

[11] R. Arulmozhiyal, and K. Baskaran, "Implementation of a fuzzy PI controller for speed control of induction motors using FPGA," Journal of Power Electronics, Vol. 10, No.1, pp. 65-71, 2010.

[12] M. Keddar, M. L. Doumbia, M. Della Krachai, K. Belmokhtar, and A.H Midoun, "Interconnection Performance Analysis of Single-Phase Neural Network Based NPC and CHB Multilevel Inverters for Grid-Connected PV Systems," International Journal of Renewable Energy Research, Vol.9, No.3, pp. 1451-1461, 2019.

[13] D. Balara, J. Timko, J. Zilkova, and M. Leso, "Neural Networks Application for Mechanical Parameters Identification of Asynchronous Motor', Neural Network World, Vol. 3, pp. 259-270, 2017.

[14] B. Pragathi and M. Suman, "Neural Network Based Photovoltaic System for Three Phase Inverter," International Journal of Pure and Applied Mathematics, Vol. 120, No. 6, pp.3021-3035, 2018.

[15] F. Lftisi, G.H. George, A. Aktaibi, C.B. Butt, and M. A. Rahman, "Artificial neural network based speed controller for induction motors," IECON 2016 - 42 $2^{\text {nd }}$ Annual Conference of the IEEE Industrial Electronics Society, 23-26, Oct. 2016.

[16] K. Nath, A. Kumar, A. Roy, and A. Sharma, "Speed control of neural network based energy efficient DC drive," International Conference on Advances in Computing and Communication Engineering, pp.318-323, 2015.

[17] S. Khomfoi, and L. M. Tolbert, "Fault Diagnostic System for a Multilevel Inverter Using a Neural Network," IEEE Transactions on Power Electronics, Vol. 22, No. 3, pp 1062-1069, 2007.

[18] A. Sharma, K. Nath, A. Kumar, and A. Roy, "Error feedback based speed control of DC motor drive for variable load torque using neural network," International Journal of Engineering Trends and Technology, Vol. 22 No.2, pp. 69-73, 2015.

[19] T. Jing, A. Maklakov, A. Radionov, S. Baskov, and A. Kulmukhametova, "Research on hybrid SHEPWM based on different switching patterns," International Journal of Power Electronics and Drive System (IJPEDS), Vol. 10, No. 4, pp. 1875-1884, 2019.

[20] M. K. Modi, S. Venugopal, and G. Narayanan, "Space vector-based analysis of overmodulation in trianglecomparison based PWM for voltage source inverter," Indian Academy of Sciences, Vol. 38, No. 3, pp. 331-358. 2013.

[21] A. Sharma, D. Singh, P. D. Singh, and S. Gao, "Analysis of Sinusoidal PWM and Space Vector PWM based diode clamped multilevel inverter," International Conference on Electrical, Electronics and Computer Engineering, pp. $1-6,2018$. 
[22] S. Bhushan, and S. Sonoli, "Starting torque and torque ripple reduction using SVPWM based vector control of induction motor with nine-level cascaded multilevel Inverter fed with solar PV power," International Journal of Power Electronics and Drive System (IJPEDS), Vol. 10, No. 2, pp. 1123-1132, 2019.

[23] E. A. R. Engku Ariff, O. Dordevic, and M. Jones, "A Space Vector PWM Technique for a Three-Level Symmetrical Six-Phase Drive," IEEE Transactions on Industrial Electronics, Vol. 64, No. 11, pp.1-6, 2016.

[24] T. Trivedi, P. Agarwal, R. Jadeja, and P. Bhatt, "FPGA Based Implementation of Simplified Space Vector PWM Algorithm for Multilevel Inverter Fed Induction Motor Drives," World Academy of Science, Engineering and Technology, Vol:9, No. 8, pp.1144 -1149, 2015.

[25] B. K. Bose, "Neural Network Applications in Power Electronics and Motor Drives-An Introduction and Perspective," IEEE Transactions on Industrial Electronics, Vol. 54, No. 1, pp. 14-33, 2007.

[26] X. Li, Z. Deng, Z. Chen, and Q. Fei, "Analysis and simplification of three-dimensional space vector PWM for three-phase four-leg inverters," IEEE Transactions on Industrial Electronics, Vol. 58, No.2, pp. 450-464, 2011.

[27] R. Krishnan, "Electric motor drives modeling, analysis, and control," published by Prentice Hall of India Private Limited, pp. 410-510, 2006.

[28] N. Pimkumwong, and M. S. Wang, "Online Speed Estimation Using Artificial Neural Network for Speed Sensorless Direct Torque Control of Induction Motor based on Constant V/F Control Technique," Journal Energies, MDPI, pp.1-14, 2018.

[29] K. S. Deshmukh, K. Bansal, and A. Killedar, "Modeling and Simulation of Three Phase Induction Machine Using Written Pole Technology," IOSR Journal of Electrical and Electronics Engineering, Vol. 12, No. 1, pp. 23-29, 2017.

[30] N. Mohamed, T. Hamza, and Gasbaoui Brahim, "Novel DTC induction machine drive improvement using controlled rectifier for DC voltage tuning," International Journal of Power Electronics and Drive System; Vol. 10, No. 3, pp. 1223-1228, 2019.

[31] Dinesh Kumar, "Performance Analysis of Three-Phase Induction Motor with AC Direct and VFD," IOP Conf. Series: Materials Science and Engineering, pp. 1-10, 2018.

[32] T. Ali, A. Y. M. Abbas, and E. H. A. Osman, "Control of Induction Motor Drive using Artificial Neural Network," Journal of Engineering and Computer Science, Vol. 15, No. 2, pp.1-7, 2014.

\section{BIOGRAPHIES OF AUTHORS}

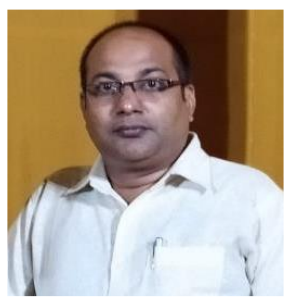

Mr. Akhilesh Sharma is working as Assistant Professor at North Eastern Regional Institute of Science \& Technology, Nirjuli, Arunachal Pradesh, India. He did his Bachelor's degree in Electrical \& Electronics Engineering from Malnad College of Engineering, Hassan, Karnataka, India in 2002 and thereafter a Master's degree in Power Electronics \& Drives from Madan Mohan Malaviya Engineering College, Gorakhpur, India, in 2009. He has over a decade of teaching experience for under-graduate students and almost five years at post-graduate level. So far, he has attended and presented many papers in IEEE conferences and published 4 research papers. His research interests include Modeling and Analysis of Power Electronic Converter circuits, Electrical Machines \& Drives.

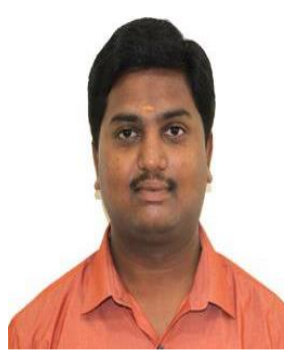

Mr. Anandh N. obtained his B.E degree in Electrical and Electronics Engineering from Ranipet Engineering College, Anna University, Chennai in 2006 and M.Tech degree in Power Electronics, Electrical Machines and Drives from Indian Institute of Technology Delhi (IIT-D), New Delhi in 2014. He also obtained his M.B.A degree from Directorate of Distance Education, Pondicherry University, Puducherry. Currently, he is an Assistant Professor in the Department of Electrical and Electronics Engineering at Manipal Institute of Technology, a constituent unit of Manipal Academy of Higher Education (Deemed to be University), Manipal, Karnataka. He has over a decade of teaching experience for under-graduate students and almost five years at postgraduate level. His research interests include Modeling and Analysis of Power Electronic Converter Circuits, Soft-Switching Power Converters, Electrical Machines \& Drives, Application of Power Electronics in Power Systems, Power Quality and Harmonic Analysis. He is a life member of ISTE and ISCA.

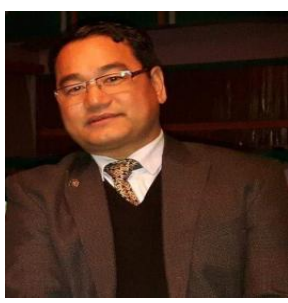

Dr. Sarsing Gao obtained his PhD degree in Electrical Engineering from Indian Institute of Technology, Delhi, India in 2012. He completed his M. Tech from IIT, Roorkee, India, in the year 2001 in alternate hydro energy systems. Currently, he is a Professor in the Department of Electrical Engineering at North Eastern Regional Institute of Science \&Technology, a deemed to be university, under the ministry of human resource and development, Government of India. He has vast teaching and research experiences which spread over two decades. His research interests include Electrical Machines, Distributed Power Generation, Energy and Power Quality. He is a senior member of IEEE and life member of ISTE. 